\title{
Adult literacy and liberal-progressive pedagogy: Australian contexts
}

\author{
Stephen Black and Barbara Bee
}

School of Education, University of Technology Sydney, Australia (both authors)

Corresponding author: Dr Stephen Black, School of Education, Faculty of Arts and Social

Sciences, University of Technology Sydney, Building 10 Level 4, 235 Jones Street,

Broadway NSW 2007, Australia.

Email: stephen.black@uts.edu.au ; Telephone: 61295145286

UTS web profile available at: https://www.uts.edu.au/staff/stephen.black

Dr Barbara Bee, School of Education, Faculty of Arts and Social Sciences, University of Technology Sydney, Building 10 Level 4, 235 Jones Street, Broadway NSW 2007, Australia. Email: barbara.bee1@gmail.com

Disclosure statement: Both authors declare that they have no financial interest or benefit arising from the publication of this article

Short biographical notes on contributors:

Stephen Black is an Honorary Associate and researcher in the School of Education, University of Technology Sydney (UTS). He has been involved in the field of adult literacy for more than three decades, initially as a teacher in prison education and NSW TAFE, then as a front-line manager in NSW TAFE, and more recently as a researcher at UTS. He works within an understanding of literacy as critical social practice and has researched the role of literacy in the lives of many marginalised groups, including prisoners, local council workers, TAFE students, production workers and patients at a diabetes centre.

Barbara Bee was a TAFE teacher in NSW for over three decades where she worked almost entirely with marginal adult learners. Her recent $\mathrm{PhD}$ at the University of Technology Sydney was an historical account of transformative teaching and learning in three TAFE programs for educationally and economically disadvantaged adults. She has a particular interest in the pedagogy of Paulo Freire and has written extensively about critical literacy in relation to disenfranchised learners and its application to the design and implementation of cross-cultural curricula for women in the NSW TAFE system. 


\section{Adult literacy and liberal-progressive pedagogy: Australian contexts}

This article explores adult literacy pedagogy in the Australian vocational education and training (VET) sector which has long provided most adult literacy programmes. We draw on semi-structured interviews with a small group of eight teachers undertaken in 2005 as part of a project on the social capital outcomes of adult literacy programmes. Through highlighting various elements of student-centred pedagogy, the aim is to demonstrate what is commonly referred to as liberal-progressive pedagogy. We discuss how some educators in this pedagogical tradition have incorporated critical literacy, while others have critiqued it as largely accommodating the status quo. Since the mid-1990s however, the field of adult literacy in VET has been increasingly colonised by neo-liberal ideology which sees literacy equated with human capital. Consequently, adult literacy pedagogy in VET in recent times fits within an industry-dominated, competency-based and nationally accredited VET system in which, we argue, the curriculum provides few spaces for liberal-progressive pedagogy. As teachers express their concerns at the possible demise of liberal-progressive pedagogy in adult literacy in VET, it is timely to reflect on its key elements and its value for social justice.

Key words: adult literacy, pedagogy, liberal-progressive, social justice, neo-liberal

Original article

\section{Introduction - the beginnings of adult literacy provision and student-centred pedagogy}

In this article, we examine adult literacy pedagogy in Australia which traditionally has been student-centred and termed liberal-progressive. This form of pedagogy reached its zenith in TAFE (technical and further education) in the 1980s and early 1990s, and we explain the key elements of this pedagogy as it was practiced in a TAFE college in New South Wales (NSW) in 2005. At this time the adult literacy programmes in this college retained a traditional student-centred pedagogical focus. We analyse data from semi-structured interviews undertaken with a small group of eight adult literacy teachers in the TAFE college in order to demonstrate various elements of student-centred pedagogy. These interviews were undertaken as part of a larger project exploring how adult literacy programmes resulted in social capital outcomes (Balatti, Black and Falk 2006). We argue that liberal progressive adult literacy pedagogy has social justice value, in particular when this pedagogy incorporates critical literacy. In the current neo-liberal climate, however, the spaces for liberal-progressive pedagogy in adult literacy in TAFE, and VET generally, are very limited. In light of concerns about the imminent demise of this form of adult literacy pedagogy, this article aims to document it for public memory (McCormack 2016) as a reminder of a time when educational paradigms were underpinned by a different set of values, and also to indicate its future direction.

Adult literacy as a disciplinary field effectively began in Australia in the mid-1970s and closely mirrored developments in the UK (as outlined by Hamilton and Hillier 2006). Provision started mainly with volunteer tutors working on a one-to-one basis in the local community with individuals who wanted to improve their literacy abilities. By the 1980s, as government funding became available, provision shifted more to small-group tuition and 
increasingly in institutional settings, mainly with paid teachers in TAFE. In each state in Australia provision developed slightly differently, but in NSW, the most populous state, by the mid-1980s adult literacy was considered a 'growth business' (Rustomji and Dent 1986) in TAFE colleges. TAFE at the time, as Australia's public VET system, was modelled on social democratic values following the election of Gough Whitlam as Prime Minister in 1972 and the report his government commissioned into VET, known as the Kangan report (Australian Committee on Technical and Further Education 1974). As a result, all courses were feeexempt, there was a plethora of 'equity' courses on offer in addition to traditional vocational courses, and TAFE encouraged the participation of disadvantaged groups, who we refer to elsewhere as primarily working class people (Black and Bee 2017).

In this paper, we use the term adult literacy for consistency and for the historical linkage with its origins, but we need to recognise that nomenclature has changed over the decades, in particular in the formalised provision in TAFE. In NSW TAFE colleges the term adult basic education (ABE) dominated for many years and included numeracy, and also language, reflected in the commonly used acronym LLN (language, literacy and numeracy). In recent times, the term 'foundation skills' has dominated, which we discuss later in the article.

The adult literacy pedagogy of volunteer tutors and of teachers in the institutionalised settings of TAFE was underpinned by a set of deeply held beliefs and principles, which Lee and Wickert $(1995,138)$ referred to as having the 'status of truth'. They listed them as follows:

- Student-centred and student-directed learning

- Curriculum based on student needs

- Concern with the student as a whole person

- Use student experience as a resource for teaching

- Negotiate learning with student

- Relevant and purposeful learning activities

- Learning which develops student independence

- Reflection

- Student is an active participant

- Small group learning

Student-centred learning was central to these truths, as it was also in the UK provision (Hamilton and Hillier 2006). For example, when a national series of pamphlets on Good Practice in Australian Adult Literacy and Basic Education were developed in the late 1980s, the first edition was devoted to student-centred learning (see Osmond 2016). Kath White $(1983,118)$, an early influential figure in adult literacy in NSW, used the term 'primacy of the individual' to explain this foremost principle:

The individual student's perceptions, needs, aspirations, and learning style should determine the type of tuition s/he receives, rather than any pre-conceived notions 
of ideal educational content and delivery. This includes respect for the student's right to share in decision-making about his/her educational future.

From the beginnings of adult literacy and during the early professionalisation of the field in the 1980s, these principles of always focusing on the experiences and perceived needs of individual students in a respectful, shared and non-judgmental way were almost universally understood among adult literacy teachers (Osmond 2016). They gave the field a 'distinctive identity' (Lee and Wickert 1995, 134). The close personal relationship and rapport established between students and teachers were integral in ensuring that adult literacy pedagogy differed from the often negative prior schooling experiences of many students. 'Whole language' and 'language experience' approaches to pedagogy dominated as teachers encouraged students to articulate their experiences, affirming them 'as the unique belonging of the individual', and the teacher's role was 'to develop these inner resources, through talking and listening, reading and writing' (Campbell 2010, 141). Teachers had a primary concern with developing the self-confidence and self-esteem of their students (Charnley and Jones 1980; Grant 1987) as part of the overall aim of empowering them as individuals, of 'being somebody' (Hamilton 2010, 20). As Campbell $(2010,141)$ notes, 'the language of personal empowerment, a common term in adult literacy education, belongs to this era of pedagogy'. And this personal empowerment as an outcome of adult literacy teaching was often expressed by teachers with metaphors of 'blooming, opening up, coming alive' (Hammond et al 1992, 43).

We make the point in this article that the above student-centred features of adult literacy have remained constant over the years as the guiding principles for adult literacy teachers, though the opportunities for practicing according to these principles have become limited, as we discuss later in the article.

Various elements of adult literacy pedagogy in Australia have been researched further as the field has developed. For example, there is now greater recognition that improved student self-confidence/self-esteem is related to improved connections and relationships with other people in social networks, often referred to as social capital (Balatti, Black and Falk 2006; 2009). Concern with the student as a whole person within the safe and supportive group learning environment maximises the opportunities for teachers to know more about their students, and for students to establish strong ties with other students and the wider society.

Another central element of adult literacy pedagogy that has been highlighted more in the UK than Australia is the focus on the socio-cultural contexts of literacy, on understanding literacy as social practices and how they relate to people's everyday lives (e.g. Barton et al 2007; Hamilton 2010). As we will see from the research data outlined later in this article, adult literacy pedagogy in Australia, as in the UK, is very much focused on how students use literacy/cies in their everyday lives. This social practice perspective may be seen to fit within the principle of 'relevant and purposeful learning activities' listed above by Lee and Wickert $(1995,138)$. 
In analysing the early discourses of adult literacy teaching in Australia, Lee and Wickert (1995) raise the issue of power, and the fact that differences in power are not acknowledged in the relationships between teachers and students. This teacher-learner relationship assumes 'a reciprocity, if not equality between teacher and learner' which implies 'a refusal of social difference, as if "truly adult" interactions involve a refusal or transcendence of social hierarchy' (141). Lee and Wickert (1995) relate this aspect of power relations in the adult literacy classroom, along with the student-centred pedagogical principles mentioned above, to the discourse of liberal-progressivism.

\section{Liberal-progressivism}

Liberal-progressivism has long been viewed as a distinct educational orientation or philosophy. Kemmis $(1983,9)$ for example, describes three such orientations: 'vocational/neo-classical', 'liberal-progressive', and 'socially-critical'. The 'vocational/neoclassical' orientation sees education as preparation for work, whereas the 'liberalprogressive' orientation sees education as preparation for life. This orientation sees education for the 'whole person', as a 'personal value to be developed rather than as a set of tools to be used for work' (9). It aims to develop the individual autonomy of students as a way of improving society. The 'socially-critical' orientation on the other hand links knowledge with action. It involves developing critical thinking and self-reflection about social problems and collective action to execute social change.

Liberal-progressivism plays a major role in the various philosophies of adult education. Beder (1989) for example, refers to its amalgam of liberal views, which 'focus on cultivation of the intellect' (44) and enable an informed citizenry essential for democratic order, and progressive views that 'learning should proceed from experience' (45) i.e. learnercentred education involving the teacher 'as a guide and facilitator rather than as the guardian of knowledge' (45). Beder (1989) distinguishes the liberal-progressive tradition from what he terms countercritique (which includes critical Marxist and Freirean approaches), and the personal growth tradition. Similarly, other adult educators such as Merriam and Brockett (2007) use the terms liberal-progressive, behaviourist-humanist, and critical. Liberalprogressivism is considered a prevalent pedagogical model in adult education, and especially in areas such as "community education, remedial education for the "disadvantaged", and second chance education' (Findsen and Formosa 2011, 26). Almost invariably adult educators and researchers stress the role of liberal-progressive pedagogy as a vehicle for individual creativity and social advancement, the education of the whole person through relating knowledge to experience, and the ideal of societal improvement. But importantly, as critical educators point out, while liberal-progressivism argues for social improvement and a more democratic society, it does not necessarily extend to supporting the radical social transformation of society (Grollios et al 2016).

\section{Critical pedagogy}

As the above classifications of educational philosophies/orientations indicate, liberalprogressivism is usually distinguished from various 'critical' philosophies, and yet, there is 
also an assumption by some that they are part of the same philosophical strand, in particular in the field of adult literacy. McLaren $(2000,11)$ for example, writing about the critical pedagogy of Freire, states:

... at the level of classroom life Freirean pedagogy is often erroneously perceived as synonymous with whole-language instruction, adult literacy programmes, and new 'constructivist' approaches to teaching and learning based on Vygotsky's work. Not all such programmes are necessarily Freirean, but need to be judged in relation to the contextual specificity of their philosophy and praxis.

McLaren $(2000,12)$ states further that liberal-progressives are often drawn to Freire's work, but in practice, 'critical literacy' is often found to be 'domesticated and reduced to studentcentred learning approaches devoid of social critique'. This may well be the case with many adult literacy programmes in the Australian TAFE system where traditionally educators have indicated the pedagogical influence of Freire, and especially in light of Freire's visit to Melbourne in 1972 (Campbell 2010). Only very rarely, however, do we find documented examples of explicit Freirean pedagogy in Australian adult literacy (for example, Bee 1990; 1993; 2014), though there are numerous examples of teachers claiming to be inspired by Freire. Osmond (2016) for example, in researching the perspectives of adult literacy educators, cites one teacher who claimed 'One of my underpinning [principles] is still 'liberating, not domesticating' (p. 16). Analyses of the actual practices of these educators however, suggest a far less liberating pedagogy, to the extent that Osmond $(2016,16)$ concludes: 'It is doubtful ... that Freire would recognise anything of his emancipation ideology in the pedagogy that was actually practiced'.

Freire's influence is explicit in the work of Bee $(1990 ; 1993 ; 2014)$, one of the pioneers of Freirean pedagogy in Australian adult literacy. Bee $(2014,174)$ worked with mature-aged, disadvantaged women in TAFE programmes that she described as 'radical spaces for women to cross the boundaries of traditional gendered views of knowledge as well as raising expectations'. Bee (1993) demonstrated for example, how generative words such as 'wife', 'mother', 'woman' could be used for dialogue in the classroom to challenge traditional views of women's lives and lead students to become 'active participants in critically analysing social expectations of women's roles' (115). From her Freirean perspective, Bee is critical of some aspects of adult literacy pedagogy as it is practiced, in particular the focus on mastery of individual self-expression and creative writing. She writes:

... someone says they love cooking, and so the teacher structures all the adult literacy teaching and learning activities around recipes and cookery books to encourage the interested party to develop reading skills through this solo activity; but no attempt is made engage the whole group to share and talk about different food customs and cultures, famines and farming methods which could lead to a more focused social and political project for everyone to join in. (Bee 2014, 42)

We thus reinforce the point in this article that liberal progressive adult literacy pedagogy should be separated from critical pedagogy if it fails to link classroom activities and the lives 
of students with critical politics involving social and material relations in the wider society (Lankshear and McLaren 1993). As we have suggested recently in another publication, social class may play a role in the relative absence of critical literacy agendas in adult literacy classrooms because the largely middle class backgrounds of teachers may not prepare them well for fully understanding the structural inequalities that in turn affect the lived realities of the students they are teaching (Black and Bee 2017). As critical educators have pointed out, for too long the teaching of literacy (in particular in schools) has been subjugated 'to the political and pedagogical imperatives of social conformity and domination' (Giroux 1988, $62)$.

\section{Neo-liberal reforms and adult literacy pedagogy}

As we have indicated, adult literacy as a disciplinary field in Australia developed from the social democratic political era of the early/mid-1970s which underpinned equity programmes in TAFE. From the late 1980s however, the socio-political climate began to change as governments shifted their educational priorities to a focus on skill formation (Dawkins and Holding 1987). The 1991 Australian Language and Literacy Policy (ALLP, see DEET 1991) reflected this shift as it heralded a heightened role for literacy in the economy with literacy assuming primarily the status of human capital. Similar shifts occurred in the UK, and have been described as a shift 'from intrinsic values to instrumentalism' (Ade-Oje and Duckworth 2015). Henceforth, literacy in Australia has been viewed conceptually, not so much as an intrinsic good, but as integral for individual job success, the profitability of enterprises, national productivity and international competitiveness (Lo Bianco and Wickert 2001). Adult literacy education as a field had moved 'from the billabong to the mainstream' of VET (Kell 1998), but primarily within a human capital discourse that reflected dominant market-based (i.e. neo-liberal) ideology. Thus, most federal government adult literacy funding from the early 1990s has been directed to specific workplace and jobseeker programmes (Black and Yasukawa 2014; Black and Bee 2017). National training reforms brought significant changes to VET courses, including adult literacy, as all curriculum and assessment became competency-based, nationally accredited and founded on industry training packages. And to ensure the standardisation of practices and total compliance with this industry training system, audit systems have become ever more comprehensive and onerous (Black 2010; Black and Reich 2010). In time, even the term literacy has been officially supplanted with 'foundation skills', because under a human capital model and with the need for a new national policy/strategy, a new definition of literacy was required that linked the traditional skills of language, literacy and numeracy with employability skills (SCOTESE 2012).

Adult literacy provision was and continues to be affected in myriad ways by neoliberal policies. Most obviously, many programmes were rationalised to better reflect federal and state government policy, and many 'equity' programmes in TAFE declined or were abandoned altogether from the late 1980s. Designated women's programmes, for example, which invariably featured adult literacy provision, were closed by an incoming NSW state liberal/conservative government (Bee 2014), and other equity programmes progressively declined through restructures and budget cuts. Equity increasingly played a subservient role to skills as competitive market-based ideology dominated in VET. Course fees for example, 
were introduced, despite the early lobbying successes of adult literacy professional associations (NSW Adult Literacy and Numeracy Council 2003) and teacher unions. Over time, small group adult literacy provision in TAFE shifted from a curriculum focus on general education (intrinsic values) to more specific vocational skills, and adult literacy pedagogy necessarily changed also. Most significantly, the practice of teachers and students jointly 'negotiating' curriculum based on students' expressed needs was rendered problematic as every TAFE course had prescribed learning outcomes and the audit culture demanded total compliance in documenting how these outcomes were achieved for every student (Black 2010; Black and Reich 2010). As indicated earlier, similar education and training trends were occurring in other OECD nations. In the UK, for example, literacy researchers commented that the system of adult literacy provision under the Skills for life initiative was 'designed for learners rather than with them or by them' (Hamilton, Hillier and Tett 2006, 7).

As neo-liberal policies focusing on work skills have dominated adult literacy provision in recent times, issues to do with pedagogy seem to have fallen away. While once there were heated professional debates about critical literacy and 'genre versus whole language' which captured the professional interests of teachers, they are now largely absent. For example, in a study of TAFE adult literacy teacher perspectives in several focus groups (Black 2010), one teacher commented:

We don't speak about pedagogy much, but I don't think anybody does either. I haven't seen new ideas around at all, reading theory, writing theory, what's new? Maybe it's there, but we're not seeing it. No professional development, no one speaks about pedagogy anymore. (15)

This comment reflected the almost complete absence in recent times in NSW TAFE of opportunities to discuss pedagogy in professional forums. This included for example, the absence of TAFE annual conferences for adult literacy and numeracy which had been a strong feature of working in TAFE in the 1980s and 1990s, and the loss through funding cuts of important professional development agencies such as the Adult Literacy Information Office (Johnston, Johnston and Kelly 2001). Critical literacy had also fallen off the agenda. One teacher commented: 'I feel that the critical literacy kind of got lost along the way and there's nothing within the curriculum that promotes it and reinforces it' (15).

Some teachers in the focus groups felt they were not trusted anymore in a tightly regulated audit culture, indicating loss of agency. This response of course is not specific to adult literacy. In educational domains generally, neo-liberal policies have de-professionalised teachers and replaced their agency with prescriptive curriculum and oppressive regimes of testing and inspection (e.g. Biesta 2016; Rudd and Goodson 2017). On the other hand, other teachers in the focus groups demonstrated degrees of resistance to the new regulatory regimes through various compromises involving working the interstices (cracks) in the system, in order to teach essentially as they always had. Other studies similarly indicated that experienced and 'expert' adult literacy teachers could still find ways of responding to the individual goals and needs of students despite narrowly defined, prescriptive curriculum (Widin, Yasukawa and Chodkiewicz 2012). But the situation with teachers new to the field, 
those who replace the ageing adult literacy teaching workforce, was less clear. One teacher commented in a focus group that new, lesser trained teachers (i.e. those with only the basic qualification to teach in Australian VET, an industry-based Certificate IV) may not have 'a philosophy of education'. Another teacher stated:

There's going to be a vacuum and I'm worried about what's going to fill that vacuum. There won't be enough of us with all of the knowledge that we've got to keep what's special about it. (Black 2010, 20)

We maintain that what these teachers mean by 'a philosophy of education' and 'what's special' about adult literacy pedagogy, is the liberal-progressive tradition that we have outlined in this article. And the message from teachers in the field is that neo-liberal reforms have threatened its viability, or at the least, its sustainability in adult literacy provision in TAFE. It is timely therefore, to examine the nature of this pedagogy that teachers perceive is being threatened, at least in part as an exercise in public memory (see McCormack 2016). In the following section we draw on research data with a small group of adult literacy teachers that explore and reflect in more detail on liberal-progressive pedagogical practices.

\section{Research project and method}

The research data examined in this article form a small part of interview data collected for a larger study examining the social capital outcomes of adult literacy and numeracy courses (Balatti, Black and Falk 2006). These interview data were unused in the original study which focused more on student perspectives than teacher perspectives. In this article, we analyse the pedagogical perspectives of eight teachers who taught in a literacy programme in one TAFE college located in a metropolitan suburb of Sydney. At the time (in 2005), these classes retained a traditional adult literacy orientation in so far as they were free courses open to anyone in the community, and despite the creeping regulatory pressures of accredited courses, they focused on general education based on the expressed needs of students. The classes comprised either small groups of approximately 8-10 students, or larger groups of approximately 15-20 students.

The teachers interviewed were all female and highly experienced in adult literacy, each having taught in the field for at least 15 years. Most were aged in their 50s; two were in their mid-40s. Two of the teachers co-taught one of the larger groups. Typical of many adult literacy teachers, these teachers had first degrees, followed by a diploma in teaching, and had at one time taught in the school system. All but one of the eight teachers had obtained post graduate qualifications in adult basic education or ESL studies.

Most of the students in the classes were older students from culturally and linguistically diverse backgrounds. Countries of birth included China, Korea, Afghanistan, Iran, Armenia, Russia, and Romania. And because the TAFE college provision was quite extensive with approximately 200 adult literacy students and many classes, they were grouped in classes according to literacy 'levels'. Thus there were small-group classes (8-10 students) of lower level students and larger-group classes (15-20) of higher level students. 
The research approach was qualitative (Denzin and Lincoln 2005) and designed to explore and then build new knowledge and theory, in particular, to understand how outcomes (social capital outcomes in the larger study) and inter-relationships occur (Balatti, Black and Falk, 2006, 13). At the time, there were no studies of social capital outcomes from adult literacy programmes, and a qualitative approach was considered appropriate for an initial study to explore if indeed there were social capital outcomes, including the range of students' social networks, their nature, and the role of the adult literacy pedagogy in producing them. The study was limited in so far as it focused on a small group of experienced adult literacy teachers in just one TAFE college, thus making it problematic to generalise the findings across the adult literacy teaching workforce. Nevertheless, the teachers interviewed in the study did closely fit the profile of the adult literacy teaching workforce at the time in terms of age, gender, qualifications, experience and pedagogical practices (McGuirk 2001).

Interviews were semi-structured (Patton 1990) with each interview lasting approximately one hour and undertaken within the college. The main focus in the interviews was on how teachers decided what to teach, and the types of strategies that seemed to work well. Interviews were audio recorded and later transcribed in full.

The research was approved by the James Cook University Human Research Ethics Committee.

\section{Findings and discussion}

Interview data in this section are organised under themes representing what teachers indicated were the essential elements of their adult literacy pedagogy, and they are related to the principles and practices outlined in the literature cited earlier in this article.

While each of the teachers had their own personal teaching styles, and while some of their classes differed in terms of numbers of students, their backgrounds and their ability levels, it was nevertheless clear that student-centred learning within a liberal-progressive pedagogical tradition dominated their practices.

\section{Student-centered, student-directed learning}

Student-centred approaches to pedagogy were particularly apparent when teachers explained how they decided what to teach, that is, the topics they decided to focus on in the lessons. One teacher with a new group of mainly female, low-level literacy students mostly in their 40s from Afghanistan, Korea, China and Hong Kong, explained her approach as follows:

First of all, usually at the start of the year I start off with the family and they bring in photos and that way I get to know about them and they also get to know about the other students and their family relationships ... so we do family stories, and then from there on I really leave it up to the students, ask them what they would like to do ...

Other teachers were also explicit in stating the primacy of the students' expressed needs and how this was reflected in what they taught: 
... it must be the only course where the students dictate what's going to be taught, there's no actual set syllabus that you follow, the students dictate what the content of the lesson will be.

Yeah, you're not teaching a subject, you're teaching to the students' needs ... Oh I ask them, I said what are the things you are interested in, what do you want to do?

For some teachers it meant that they came to class with a largely open mind on what topic to discuss with students because it depended on what the students said they wanted on the day. For example, one teacher said someone went to the markets, so that led to a discussion about markets, and another said a student brought some biscuits to class 'and they didn't have the word for a packet of biscuits, then it sort of led on ... I said what do you call a tin of coffee or something like that'. Another teacher stated that because many adult literacy students had various problems in their lives, there was not always full attendance at classes, and so she sometimes had to decide not to do a particular topic 'because a certain person is away'. And then again, when one of her students, a chef with poor attendance due to shift work, was present at class, 'I'm going to do something about food'.

\section{Reciprocal power, negotiating learning}

The issue of power relations between teachers and their students was mentioned earlier (i.e. 'a reciprocity, if not equality between teacher and learner' - Lee and Wickert 1995, 141), and teachers seemed to be in accord with this, emphasising that they did not want to dictate terms in the classroom. For example, in the following quote one teacher is at pains to stress that she is just there to help students learn, not to impose learning on them:

... initially with a new group of students they usually don't know me and I don't know them so well, but I always with the students want them to make the decisions. I give them choices if they find a decision hard to make, because, you know how they, you're the teacher, and I always sort of say no, that's not the case, you're the one doing the learning and I'm just here to help you learn ...

All the teachers stressed that the curriculum was negotiated with students based on what the students wanted. It meant sometimes that the teacher might come up with a list of topics, but these would be discussed with students to determine what should be taught, as with the following example:

... in fact I actually asked them last week, do you want to work on a particular theme, do you want spend the next few weeks talking about health issues, or shall we talk about the government, or do you want to talk about some hobby or country or whatever? 
Some teachers said they started their literacy programmes with brainstorming ideas for learning topics followed by discussion, and then they will make a democratic class decision: '... well it looks like the majority of people would like to learn something about this ...' Another teacher said a formal class vote was taken to determine the themes chosen for the term.

This type of democracy in the classroom and the reluctance of teachers to impose their views on students encouraged teachers and students to work closely together in a partnership that the teachers at least liked to consider was equal. One teacher commented: 'I am sure they treat us as friends, really'.

\section{The student as a' whole person'}

In the liberal-progressive adult literacy classroom the pedagogical focus goes beyond the technical literacy needs of individual students to incorporate the personal (i.e. the 'whole') lives of students. As one of the teachers stated: 'you're interested in each person and you get to know them individually, and their families, at very much that individual level, instead of the one out front of the mass of students'.

As we have seen, one teacher began her programme with new students by asking them to bring in photos of their family in order to explore family backgrounds and relationships. In this way, teachers began to know much about the personal lives of students. And as classes progressed, teachers often became aware of some deeply personal issues for individual students. One teacher for example spoke to a student who seemed to be distressed in class: 'Oh, she was looking really unhappy one day, and just when everybody had left, and she was the last to leave, and so I just spoke to her then ...' The teacher then learnt that this Afghan women and her children were living in an abusive home environment in which she was 'dictated by her brother-in-law'. Eventually the student moved out of that environment into a women's refuge, and she kept the teacher informed to the extent that sometime later the teacher claimed: 'And she is just so happy now, just moved on with her life'. Another teacher as part of her teaching activities to improve student writing, encouraged her students to correspond with her personally, and she would respond to them personally in writing. This two-way letter-writing dialogue led to students writing about many aspects of their personal lives. For example, one student wrote about her dilemma of how to get her mother's ashes brought from Hong Kong to Australia, and the teacher provided details of where to seek information. In another example, a student wrote that he had a passion for dancing. In these cases and many others, teachers developed close, indeed very personal and caring relations with their students and learnt much about them beyond their particular literacy difficulties. These affective aspects, as other recent studies have indicated (e.g. Feeley 2014), are not incidental but central to liberal progressive pedagogy in adult literacy.

\section{Relevant and purposeful activities - literacy as social practices}

The socio-cultural contexts that teachers drew upon in their classrooms and beyond for literacy learning were many and varied, and necessarily related to the expressed needs of students as negotiated with teachers. And clearly the demographic backgrounds of students 
influenced these classroom contexts and the flavor of the classroom activities. As we have indicated, most of the students in these classes were culturally and linguistically diverse, with many students from China, Korea, Afghanistan, Iran and Eastern Europe. They were also older students, and in the day time classes, mainly female (night classes often included younger, male students who were employed during the day). When teachers opened up the dialogue with students about what they wanted to learn, the topics typically included 'everyday' social practices involving cooking (recipes for example), shopping (supermarkets and understanding food labels), reading and understanding the news, schooling issues relating to their children, and a wide range of health matters. These topics were part and parcel of students learning to access information, play a more active role, and live better within the Australian cultural milieu, because, as one of the teachers indicated, students may have had only limited previous opportunities to do so:

I mean, a lot of our students who come to class have been in Australia for more than 10 years, but unfortunately they've had to work and they get jobs in their own culture, like factories or whatever, where they don't use English and they don't get to meet Australians and they don't get to discuss anything outside family and work ... I think they develop an interest in Australian culture, because they ask me questions

Teachers rarely focused on specific job-related activities (the night classes were different discussed below), rather, they were more general and community-related. Teachers spoke for example of lessons focusing on how to vote in elections when students indicated they were confused over whether to put crosses or numbers in the boxes, and there were lessons on becoming blood donors and how to engage in local community volunteering networks. Health featured extensively and teachers explained they discussed any matters of concern to students:

We also talked about some touchy issues, we talked about pap smears and we talked about different sorts of cancers, we talked about prostate cancer and what prostate cancer was, and why people need to go to the doctors and have these things done, and what a smear is ...

Pedagogy was directly linked with everyday social practices through excursions, as class groups visited supermarkets to learn about food labelling, ate at various restaurants where menus and food were discussed, and visited nearby areas of interest to students, including beachside suburbs, farms, and the law courts.

Teachers of night classes explained that their pedagogy was slightly different as their students were primarily workers and teachers needed to focus on social practices of more direct relevance to their work. As one teacher explained, discussing current affairs in class was a popular activity which had implications for workplace practices:

... they just loved getting the news story of the day, and being able to understand the language that's being used, as they said to me, it's so good we can go back to work and discuss this at morning tea and at lunch. 


\section{Modelling, role plays}

In teaching new social practices teachers provided many examples of quite explicit pedagogy. One teacher stated that she was 'leading them towards being able to communicate in the written form and verbally in small groups in a more confident manner'. This often involved the modelling of specific social practices in role plays, followed by attempts at scaffolding the students towards mastery of the practice. The following comments provide an example of modelling:

One of the guys, M, he had some information from one of the doctors that was written in medical terminology and he said he needed to have this clarified, and we talked about how you would go and ask questions to his local doctor, so he had a load of questions he then took back to his doctor, so we had practiced first and then he felt he could then go and ask questions.

Other teachers explained how they did role plays on how to vote, and how to make enquiries on the telephone. Typically, the teacher structured the role plays so that students would practise first with a partner, then in small groups, and then as their confidence grew, present the role play to the whole class.

In many ways this pedagogical focus on everyday social practices and the use of role plays demonstrated that the adult literacy classes were in a sense a 'practice-field ... a new and safe environment in which to play out new aspects of identity and practise new skills' (Balatti, Black \& Falk 2007, 12).

\section{The power of the class group}

While the point has been made that teachers learn much about the lives of individual students and often develop a strong personal rapport with them, it is the whole class, 'the group', that is of prime concern for teachers. Teachers spoke about trust, friendship and social cohesion within the group and how the group provided strong emotional support for its members. For example, one teacher recounted that one of her students in her night class was being bullied at work by fellow workers who resented his promotion. The teacher allowed the issue to be discussed in class and she commented: 'people just said to him, hang in there, or whatever it was, and it stopped after a while ... it just showed that the class was supportive of him ...' There were many cross-cultural examples also, of students sharing their views on religious beliefs and customs and generally finding the class group to be receptive and supportive. There were also occasionally situations where an individual student transgressed the norms of the class group causing difficulties for teachers. In the case of one student who was acting in a demanding and belligerent manner, the teacher had to explain to him the effects it was having on the class group, and on a separate occasion (when the student was absent) she felt the need to apologise to the rest of the class for allowing the disruptions: 'I wanted to acknowledge that I realised that they had suffered his insults and his rudeness and bluntness ... I guess I was just feeling guilty myself for not having spoken up in the class'. Following her private talk with the student, and the patience and support of the rest of the class, the student then became a lot more accommodating with the class group: 'listening to the others 
and talking to them and not telling them where they are wrong, telling them they've made a mistake ... a dramatic turn-around, dramatic turn-around'.

\section{Personal empowerment}

All the teachers expressed in various ways that their pedagogy was aimed at empowering students individually and that it involved developing their students' self-confidence. This finding should hardly be surprising as student self-confidence has long been established as a bedrock aim and outcome of adult literacy provision (e.g. Charnley \& Jones 1980, Grant 1987). This was indicated, for example, with the teacher cited earlier, who learnt that one of her Afghan students was in an abusive situation at home and eventually left to live in a women's refuge. The teacher was asked if this student's participation in her class had much to do with her life outside, and the teacher commented:

I'm sure it did, because I feel that being in the class, I feel that would have boosted her confidence, you know, confidence within herself, and boosted her self-esteem to some extent to, to feel that she could do this ...

There were many other examples provided by the teachers of students learning more about an area of knowledge in the classroom and then developing the self-confidence to display greater agency in social situations in their everyday lives. One student, for example, was prepared to now question her doctor:

... she went back to the doctor and talked to him and said "why is this not working for me?' And that was something she had not done before, she had not questioned the doctor in what he had said was wrong with her, and her symptoms did not fit with what he was saying, so she went back and asked for clarification and said 'Look, I'm not happy with this', now that's something that she wouldn't have done before.

Improved self-confidence was also evident in how students carried themselves, in their body language. One teacher recounted how a Chinese student was changing in his confidence and demeanour demonstrated in the way he invited other students to join his group:

... and he sort of said come and sit here and we can discuss this together, big smile, and very positive, open arm movements, and very open body language and that was really, really encouraging to see, and that was something that was, it's only just recently starting to occur, so he's feeling more confident within himself and more able to be more welcoming.

Another teacher noted how a student now carried herself more confidently as a conscious response to the teacher in the classroom:

As I was saying, some of them are now opening up ... say M, used to hide when she didn't understand, so the head would go down, and now she, as soon as she realises her head is about to go down, she looks up and she 
smiles ... I've seen her outside and she is now sort of trying to lift her head, the chin's come up ...

These kinds of observations would appear to accord with the metaphors cited earlier of adult literacy students 'blooming, opening up, coming alive' (Hammond et al 1992, 43).

\section{But not critical literacy}

While the teachers worked towards individual student empowerment, and while in a Freirean sense there was an apparent equality in the relationships between teachers and students and knowledge was not simply deposited from one to the other (as in 'banking' education), it was nevertheless a limited form of empowerment. It was not emancipatory in so far as there was little evidence of a focus on the broader politics, an explicit focus on how power is reproduced through dominant discourses in society (see Galloway 2015). Empowerment for these teachers was primarily about developing individual students' self-confidence and agency to enable them to better manage their life's circumstances, but whether this extended to student 'transformation' of the kind Duckworth $(2013,2015)$ explains in her UK adult literacy study, or Bee's (2014) work with women's groups in NSW, is unclear. While no doubt there were individual cases of students feeling better about themselves and demonstrating individual agency (the case of the Afghan student for example), there was little evidence that the teachers explicitly promoted critical literacy in their pedagogy. Topics such as elections were discussed in the classroom, but the focus was on the technicalities of how to vote properly, not who to vote for and how different political parties represented different sectional interests. Health was a topic of discussion primarily to increase knowledge for improving one's personal and family health, not to understand why some communities in Sydney experienced poorer health than other communities based on their socio-economic status. And issues of gender for the mainly female student population appeared not to venture much beyond local social practices such as cooking, shopping and schooling issues for their children.

As we suggested earlier in this paper, the social class composition of the adult literacy teaching workforce may influence the extent to which broader politics play a part in the classroom. But there are a range of other factors as well, including that students attend adult literacy classes for a number of reasons, and not all of them may want for critical consciousness. This was a point made by Hamilton and Hillier $(2006,116)$ in relation to adult literacy students in the UK where they point out that adult literacy can be taught from within a range of different purposes - liberal, radical or vocational, and thus: 'Learners helped to read to their grandchildren are not seeking empowerment to challenge inequalities in society, or employment skills, whereas other learners are being helped to do precisely these things'. Hamilton and Hiller $(2006,116)$ describe adult literacy teachers as 'eclectic pragmatists' as they shift within various teaching approaches.

\section{Conclusions}

The pedagogical principles and practices outlined by the teachers in this study were recorded in 2005 , more than a decade ago. Whether they were typical of adult literacy teachers in other 
TAFE colleges at the time is difficult to determine, except that these principles and practices corresponded closely with those outlined by Lee and Wickert (1995) a decade before, which in turn related to the earliest two decades of adult literacy in Australia. We could thus argue that the discourses of adult literacy pedagogy, and in particular the student-centred elements that we have referred to as liberal-progressive, appeared to be constant and robust. Lee and Wickert (1995) further noted the absence of liberationist discourses, and likewise in this study we have found relatively little evidence of critical pedagogy being practiced. If we then move forward another decade or so to the current state of adult literacy provision in a neoliberal TAFE system, subject to all the regulatory constraints of prescribed, competencybased accredited curriculum and the punitive functions of the audit culture, then we might reasonably assume that liberal progressive pedagogy, if it remains an element of the pedagogical practices of adult literacy teachers in TAFE today, can be undertaken only surreptitiously in the interstices (cracks) in the system. As educational researchers have pointed out, there is the need to 'mind the gap' that has developed between the professional beliefs of teachers and the need for compliance with standardised curriculum and audit systems (Groundwater-Smith and Mockler 2009). In the case of adult literacy, professionally teachers may seek to meet the expressed needs of students and what they individually want to achieve, but are hindered by organisational compliance with the prescribed curriculum. Teachers in adult literacy focus groups for example, have commented that 'the curriculum ... has taken control of identifying learner needs' (Black 2010, 13).

How well, or if at all, liberal progressive pedagogy survives in adult literacy in TAFE is for future research to determine. The signs to date (Bee 2014, Black 2010), however, are not good because the adult literacy (now 'foundation skills') curriculum is designed and regulated to closely fit the needs of governments and industry (Black and Yasukawa 2014), not the intrinsic values and needs of individual students. Teachers new to the field may be unlikely to have knowledge of liberal-progressive pedagogy, and as adult literacy teachers in a focus group discussion suggested, they are likely to be told: 'Here are your learning outcomes, this is your CLAMS roll (a computerised roll), and these are what you tick off for assessment validation' (Black 2010, 21). In other words, the major pedagogical focus will be on audit compliance not student-centred pedagogy. As Hamilton and Hillier (2006) note similarly with regards to the UK literacy provision, student-centred learning and accredited curriculum are ideologically in conflict with each other. And as for critical literacy, we could well argue that it is now 'twice-removed' from current pedagogical practices in TAFE, given its relative absence in traditional liberal-progressive pedagogy as this article has indicated, and its likely total absence in the current neo-liberal TAFE which aims only to develop human capital.

The future of liberal-progressive pedagogy in adult literacy in VET appears bleak because it is unlikely that neo-liberal ideology will be on the wane any time soon, and we can assume that TAFE and the VET system generally will continue to commodify education and training and regulate pedagogy ever more closely to accredited curriculum designed for human capital outcomes. And yet, ironically, we would argue there has never been a greater need for both liberal progressive pedagogy and a focus on critical literacy. Adult literacy 
students have always been the disadvantaged and the working class (Black and Bee 2017), the very people on the wrong side of growing inequalities and disparities in wealth distribution in Australian society resulting from neo-liberal policies. In the interests of social justice, there is the need for critical literacy to question the politics of poverty (Comber 2015), but that is unlikely in the contemporary adult literacy classrooms in TAFE where curriculum is designed to meet the needs of business and industry. As this article has demonstrated, liberal-progressive pedagogy offers a way of empowering individuals, and potentially through critical literacy, the means to educate about social justice, but at this historical juncture in Australian society, it may need to be promoted in community learning contexts outside formal VET/TAFE learning contexts. These learning contexts, where jobs and economic development are not the primary focus, need to be less constrained by industry regulation and thus ideally would involve non-accredited literacy programmes (Dymock 2007). A little over a decade ago, researchers with a focus on community capacity-building and developing social capital were promoting the need for literacy learning to move beyond 'stand-alone' provision in formal education and training programmes and become integrated with activities in other community sectors, including health, welfare, youth, housing and local community development (Wickert and McGuirk 2005). Recently public libraries have been promoted as a site for literacy learning (Anderson et al 2013), and they provide an example of the type of local community contexts where liberal-progressive pedagogy may be sustained and/or developed further.

\section{References}

Ade-Oje, G., and V. Duckworth. 2015. Adult Literacy Policy and Practice: From Intrinsic Values to Instrumentalism. Basingstoke: Palgrave.

Anderson, K., L. Bartlett, C. Barratt-Pugh, Y. Haig, and N. Leitão. 2013. "Better Beginnings: Public Libraries Making Literacy Links with the Adult Community." International Journal of Libraries and Information Studies 64 (4): 272-281.

Australian Committee on Technical and Further Education. 1974. TAFE in Australia: Report on Needs in Technical and Further Education. Canberra: Australian Government Publishing Service.

Balatti, J., S. Black, and I. Falk. 2006. Reframing Adult Literacy and Numeracy Courses: A Social Capital Perspective. Adelaide: NCVER.

Balatti, J., S. Black, and I. Falk. 2007. "Teaching for Social Capital Outcomes: The Case of Adult Literacy Courses.” Australian Journal of Adult Learning 47 (2): 245263.

Balatti, J., S. Black, and I. Falk. 2009. A New Social Capital Paradigm for Adult Literacy: Partnerships, Policy and Pedagogy, Adelaide: NCVER.

Barton, D., R. Ivanic, Y. Appleby, R. Hodge, and K. Tusting. 2007. Literacy, Lives and Learning. London: Routledge.

Beder, H. 1989. "Purposes and Philosophies of Adult Education." In Handbook of Adult and Continuing Education, edited by S.B. Merriam, and P.M. 37-50. In S.B. Merriam, P.M. Cunningham, 37-50. San Francisco: Jossey Bass. 
Bee, B. 1990. "Teaching to Empower: Women and Literacy." Australian Journal of Reading 13 (1): 53-60.

Bee, B. 1993. "Critical Literacy and the Politics of Gender." In Critical Literacy: Politics, Praxis and the Post-Modern., edited by C. Lankshear, and P. McLaren, 105131. New York: State University of New York Press.

Bee, B. 2014. Transformative Learning and Frontline Teaching in NSW Technical and Further Education since Myer-Kangan: An Adult Educator's Account. PhD thesis, University of Technology Sydney.

Biesta, G. 2016. Good Education in an Age of Measurement: Ethics, Politics, Democracy. Abingdon: Routledge.

Black, S. 2010. "Working the Interstices: Adult Basic Education Teachers Respond to the Audit Culture." Literacy and Numeracy Studies 18 (2):6-25.

Black, S., and K. Yasukawa. 2014. "The Literacy Myth Continues: Adapting Graff's Thesis to Contemporary Policy Discourses on Adult 'Foundation Skills' in Australia." Critical Studies in Education 55 (2): 213-228.

Black, S., and K. Yasukawa. 2016. "Research That Counts: OECD Statistics and 'Policy Entrepreneurs' Impacting on Australian Adult Literacy and Numeracy Policy." Research in Post-Compulsory Education 21 (3): 165-180.

Black, S., and B. Bee. 2017. "Adult Literacy Provision and Social Class: Australian Contexts." Studies in the Education of Adults

Black, S., and A. Reich. 2010. "The elephant in the room': Audit culture and TAFE teachers." Paper Presented at the 2010 AVETRA Annual Conference, April 7-8, Surfers Paradise.

Campbell, B. 2010. Reading the Fine Print: A History of the Victorian Adult Literacy and Basic Education Council (VALBEC) 1978-2008. Springvale Sth: VALBEC.

Charnley, A.H., and H.A. Jones. 1980. The Concept of Success in Adult Literacy. London: ALBSU.

Comber, B. 2015. "Critical Literacy and Social Justice." Journal of Adolescent \& Adult Literacy 58 (5): 362-367.

Dawkins, J., and C. Holding. 1987. Skills for Australia. Canberra: Department of Employment, Education and Training.

Denzin, N and Y. Lincoln, eds. 2005. The Sage Handbook of Qualitative Research. $5^{\text {th }}$ edition. Thousand Oaks: Sage.

DEET (Department of Employment, Education and Training). 1991. Australia's Language: The Australian Language and Literacy Policy. Canberra: DEET.

Duckworth, V. 2013. Learning Trajectories, Violence and Empowerment amongst Adult basic Skills Learners. London: Routledge.

Duckworth, V. 2015. "Literacy and Transformation." In Landscapes of Specific Literacies in Contemporary Society: Exploring a Social Model of Literacy, edited by V. Duckworth, and G. Ade-Oje, 27-46. London: Routledge.

Dymock, D. 2007. Community Adult Language, Literacy and Numeracy Provision in Australia: Diverse Approaches and Outcomes. Adelaide: NCVER.

Feeley, M. (2014). Learning Care Lessons: Literacy, Love, Care and Solidarity. London: Tufnell Press. 
Findsen, B., and M. Formosa. 2011. Lifelong Learning in Later Life: A Handbook on Older Adult Learning. Rotterdam: Sense.

Galloway, S. 2015. "What's Missing When Empowerment is a Purpose for Adult Literacies Education? Bourdieu, Gee and the Problem of Accounting for Power." Studies in the Education of Adults 47 (1): 49-63.

Giroux, H. 1988. "Literacy and the Pedagogy of Voice and Political Empowerment." Educational Theory 38 (1): 61-75.

Grant, A. 1987. Opportunity to do Brilliantly: TAFE and the Challenge of Adult Literacy Provision in Australia. Canberra: AGPS.

Grollios, G., H. Giroux, P. Gounari, and D. Macedo. 2016. Paulo Freire and the Curriculum. Abingdon: Routledge.

Groundwater-Smith, S., and N. Mockler. 2009. Teacher Professional Learning in an Age of Compliance: Mind the Gap. Dordrecht: Springer.

Hamilton, M. 2010. "The Social Context of Literacy." In Teaching Adult Literacy: Principles and Practice, edited by N. Hughes, and I. Schwab, 7-27. Maidenhead: Open University.

Hamilton, M., and Y. Hillier. 2006. Changing Faces of Adult Literacy, Language and Numeracy: A Critical History. Stoke-on-Trent: Trentham Books.

Hamilton, M., Y. Hillier, and L. Tett. 2006. "Introduction: Social Practices of Adult Literacy, Numeracy and Language." In Adult Literacy, Numeracy and Language: Policy, Practice and Research, edited by L. Tett, M. Hamilton, and Y. Hillier, 1-18. Maidenhead: Open University.

Hammond, J., R. Wickert, A. Burns, H. Joyce, and A. Miller. 1992. The Pedagogical Relations Between Adult ESL and Adult Literacy. Canberra: Commonwealth of Australia.

Johnston, B., K. Johnston, and S. Kelly. 2001. The Rise and Fall of the NSW Adult Literacy Information Office. Sydney: University of Technology Sydney.

Kell, P. 1998. From the Billabong to the Mainstream: A Teachers' Guide to Australian Training \& Literacy Policy Developments 1974-1998. Melbourne: National Language and Literacy Institute.

Kemmis, S. 1983. Orientations to Curriculum and Transition: Towards the SociallyCritical School. Melbourne: Victorian Institute of Secondary Education.

Lankshear, C., and P. McLaren, eds. 1993. Critical Literacy: Politics, Praxis and the Postmodern. New York: State University of New York.

Lee, A., and R. Wickert. 1995. "Reading the Discourses of Adult Basic Education." In Understanding Adult Education and Training, edited by G. Foley, 134-146. Sydney: Allen \& Unwin.

Lo Bianco, J., and R. Wickert, eds. 2001. Australian Policy Activism in Language and Literacy. Melbourne: Language Australia.

McCormack, R. 2016. "The Four Literacies: An Exercise in Public Memory." In Beyond Economic Interests: Critical Perspectives on Adult Literacy and Numeracy in a Globalised World, edited by K. Yasukawa, and S. Black, 185-203. Rotterdam: Sense. 
McGuirk, J. 2001. Adult Literacy and Numeracy Practices 2001: A National Snapshot. Canberra: Commonwealth of Australia.

McLaren, P. 2000. "Paulo Freire's Pedagogy of Possibility." In Freirean Pedagogy, Praxis, and Possibilities: Projects for the New Millennium, edited by S. Steiner, H. M Krank, R E. Bahruth, P McLaren, 1-22. New York: Falmer.

Merriam, S., and R. Brockett. 2007. The Profession and Practice of Adult Education: An Introduction. San Francisco: Jossey Bass.

NSW Adult Literacy \& Numeracy Council. 2003. Literacy at a Price. Sydney: NSWALNC.

Osmond, P. 2016. "What Happened to our Community of Practice? The Early Development of Adult Basic Education in NSW Through the Lens of Professional Practice Theory." Literacy and Numeracy Studies 24 (2): 3-23.

Patton, M. 1990. Qualitative Evaluation Methods. Thousand Oaks: Sage.

Rudd, T., and I. Goodson. 2017. Negotiating Neoliberalism: Developing Alternative Educational Visions. Rotterdam: Sense.

Rustomji, L., and K. Dent. 1986 Basic Education: A Growth Business. Sydney: TAFE NSW.

Standing Council on Tertiary Education, Skills \& Employment (SCOTESE). 2012. National Foundation Skills Strategy for Adults. Canberra: SCOTESE .

White, K. 1983. "Conflict, Principles and Practice in Adult Literacy." Australian Journal of Reading 6 (3): 117-127.

Wickert, R., and J. McGuirk. 2005. Integrating Literacies: Using Partnerships to Build Literacy Capabilities in Communities. Adelaide: NCVER.

Widin, J., K. Yasukawa, and A. Chodkiewicz. 2012. "Teaching Practice in the Making: Shaping and Reshaping the Field of Adult Language, Literacy and Numeracy Teaching." Australian Journal of Adult Learning 52 (1): 9-38. 